unit came about because it was easier for a general practitioner to admit a patient there.-I am, etc.,

West Middlesex Hospital,

JAMES ANDREWS.

Isleworth, Middlesex.

\section{Treatment of Enterobiasis}

SIR,-In introducing his report on the treatment of enterobiasis with a single dose of pyrvinium embonate (December 15, p. 1583), Dr. A. S. Desai states that "the piperazine group ... has to be administered over a period of 7 to 15 days in three daily divided doses to achieve good results." $\mathrm{He}$ is evidently unaware of the results achieved by Dr. J. W. Scopes and myself ${ }^{1}$ with a single dose of piperazine phosphate compounded with standardızed senna ("pripsen "). Both preparations appear to be equally effective and free from side-effects ; but pyrvinium embonate apparently suffers from the very considerable disadvantage, mentioned but not discussed by Dr. Desai, that it is ineffective against Ascaris lumbricoides, a parasite of immensely greater clinical importance amongst children in his own country and in warm climates throughout the world.-I am, etc.,

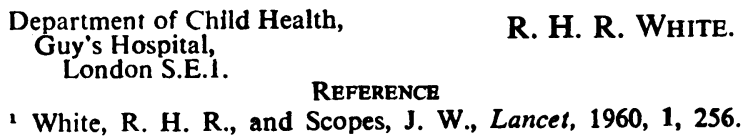

\section{Vaccination against Measles}

SIR, - The trial of a measles vaccine reported by Dr. A. P. Goffe et al. (January 5, p. 26) is a further advance. The authors quote two previous trials in this countryCollard et al. ${ }^{1}$ and Aldous et al. ${ }^{2}$-both of which were criticized $^{3}$ on the grounds that the parents may not have been sufficiently informed of or have fully understood the experimental nature of the vaccine. This criticism was widely reported in the national press.

In all these trials it is almost certain that the object of the trial and its implications were fully explained to the parents. This essential preliminary step is presumably implied in the few words, "The vaccine was offered." Would it not be better if the information given to the parents was more fully detailed? This would allay public anxiety and would avoid conjectural or unreasonable criticism.-I am, etc.,

The Royal Infirmary,
Huddersfield, Yorks. W. P. SWEetnam.

REFERENCES

' Collard, P., Hendrickse, R. G., Montefiore, D.. Sherman, P., Van der Wall, H. M., Morley, D., Goffe, A. P., Laurence, G. D., and Pollock, T. M.. Brit. med. J., 1961, 2. 1246. aldous, I. R., Kirman, B. H., Butler. N., Goffe, A. P., Laurence, G. D., and Pollock, T. M., ibid., 1961, 2, 1250. 'Pappworth, M. H., Twentieih Century. Autumn, 1962, p. 66.

\section{Whipworms in Rural Areas}

SIR,-I was most interested in the paper by Dr. N. A. Silverston (December 29, p. 1726), as whipworm infestation is also quite common in this predominantly rural area. In 1956, a 2 $\frac{1}{2}$-year-old girl came under my care from the Aran Islands with a five-month history of diarrhoea and relatively little impairment of nutrition. Diarrhoea persisted in hospital accompanied by lowgrade pyrexia and slight abdominal distension. Trichuris ova were consistently found in the faeces in large numbers; treatment with sulphonamides, neomycin, and piperazine adipate was without effect on the diarrhoea. After some weeks, proctoscopy on the ward showed a moderate proctitis, the mucosa being densely covered by adherent whipworms; the proctitis and presumed colitis were thought to be due to the whipworm infestation. Several courses of treatment with hexylresorcinol capsules by mouth had no effect. Hexylresorcinol enemata $(0.5 \%)$ were then commenced, eight being given at weekly intervals until the diarrhoea eventually ceased and the rectal mucosa returned to normal, the child's condition also improving considerably.

A 5-year-old child from Connemara was seen in 1957 with a history of intermittent diarrhoea (with occasional colic and blood streaking) for seven months. Again a moderate proctitis was seen with moderate numbers of whipworms adherent to the mucosa. One hexylresorcinol retention enema appeared to effect a cure of the symptoms. In both children trichuris ova continued to be excreted following "cure."

There happens to be another similar problem in my department at the moment, a 4-year-old girl from the Aran Islands, who was found to have considerable malnutrition: weight $24 \mathrm{lb}$. (11.0 kg.), anaemia with considerable iron deficiency (haemoglobin 27\% (3.9 g.)), and an eosinophilia (19\% of 6,000 leucocytes). She was said never to have thrived well; diarrhoea had been present for some months. Abundant trichuris ova were present in the faeces and proctoscopy showed a similar picture to that in the last-mentioned child. Treatment with dithiazanine is being given. Although no occult blood was found in the faeces on admission, some fresh blood was passed some days later. It seems likely that the anaemia in this child is more likely to be due to nutritional causes rather than to the trichuriasis, although the latter may be contributory. The two previously mentioned children did not show any significant anaemia. The well-known pica of the iron-deficient child does seem to make it more liable to acquire intestinal parasitic infection.

Dr. Silverston does well to call attention to the severe symptoms which can be caused by heavy trichuris infestation, since this does not appear to be generally appreciated. Beaver ${ }^{1}$ has stated that " heavy infections invariably produce dysentery in some degree," and Jung and Jelliffe ${ }^{2}$ regard trichuriasis as an important infection, particularly in the tropics and sub-tropics, and especially between 2 and 4 years of age.

These cases are examples of the occasional value of proctoscopy in unexplained diarrhoea in children, a further example being the infant of 5 weeks with colitis due to cow's-milk allergy mentioned by me in this journal. ${ }^{3}$ With regard to the concentration of hexylresorcinol in enemata, while Silverston used 1:300 and I used 1:200, Jung and Beaver ${ }^{4}$ advised 1:500. Dithiazanine was not available when the earlier cases were treated and would now appear to be the drug of choice.-I am, etc.,

Paediatric Department, Regional Hospital,
Galway.

B. McNicholl.

REFERENCES

1 Beaver, P C personal communication, 1956

2 Jung, R. C., and Jellifte. D. B., West Afr. med. J., 1952, 1 N.S., 11 .

McNicholl, B., Brit. med. J., 1961, 2, 1219

- Jung, R. C., and Beaver, P. C., Pediatrics, 1951, 8, 548.

\section{This Island Now}

SIR.-I am glad that you have given us such an able summary of the recent Reith lectures (January 19, p. 141), but I do not think that Professor G. M. Carstairs was sufficiently factual when, speaking of juvenile sexual 